\title{
Antitumor and Antiangiogenic Effects of the Crude Oil of Nigella sativa L. in Tumor Tissues in BALB/C Mice
}

\author{
Sima Bahramian, ${ }^{1}$ Mohammad Reza Bigdeli, ${ }^{1,}$ Bahram Rasoulian, ${ }^{2}$ and Mahdi Moridi Farimani ${ }^{3}$ \\ ${ }^{1}$ Department of Physiology, Faculty of Biological Sciences, Shahid Beheshti University, Tehran, IR Iran \\ ${ }^{2}$ Razi Herbal Medicines Research Center, Lorestan University of Medical Sciences, Khorramabad, IR Iran \\ ${ }^{3}$ Department of Phytochemistry, Medicinal Plants and Drugs Research Institute, Shahid Beheshti University, Tehran, IR Iran \\ "Corresponding author: Mohammad Reza Bigdeli, Department of Physiology, Faculty of Biological Sciences, Shahid Beheshti University, Tehran, IR Iran. E-mail: \\ bigdelimohammadreza@yahoo.com
}

Received 2015 January 20; Accepted 2015 September 05.

\begin{abstract}
Background: Products of oxidation are known to trigger cancer through damaging cellular components and angiogenesis backs tumor growth and metastasis. Antioxidant enzymes like superoxide dismutase and catalase fight the stress posed by these products. Angiogenesis inhibition offers additional benefits toward tumor suppression. Nigella sativa L. is a plant traditionally used in Middle Eastern countries for its various benefits.

Objectives: In this study, we attempted to examine the anti-tumor, antioxidant and antiangiogenic effects of N. sativa crude oil in breast tumor-bearing mice.

Materials and Methods: In this experimental study, three groups of female BALB/c mice, 5 animals in each, were respectively treated for a month with 1,2 and $4 \mathrm{~mL} / \mathrm{kg} /$ day of $N$. sativa oil 2 days after subcutaneous tumor transplantation. The fourth group, the control group, after subcutaneous tumor transplantation received distilled water. Tumor volumes, antioxidant enzymes' activity, endostatin and vascular endothelial growth factor (VEGF) amounts were measured to study N. sativa crude oil's proposed effects.

Results: In comparison with the control group, mice receiving doses of 2 and $4 \mathrm{~mL} / \mathrm{kg} / \mathrm{day}$ of $\mathrm{N}$. sativa crude oil had significantly reduced tumor volumes $(\mathrm{P}<0.005)$, less VEGF $(\mathrm{P}<0.005)$, more endostatin $(\mathrm{P}<0.05$ and $\mathrm{P}<0.005$, respectively) and increased superoxide dismutase (SOD) $(\mathrm{P}<0.05$ and $\mathrm{P}<0.005$, respectively) and catalase $(\mathrm{CAT})$ activity $(\mathrm{P}<0.005)$.

Conclusions: $N$. sativa crude oil seems to inhibit breast tumor growth partly through improving the activity of antioxidant enzymes' activity and partly by suppressing angiogenesis. Yet, more studies are required to intensely clarify the other involved mechanisms.
\end{abstract}

Keywords: Antioxidant Enzyme, Anti-Angiogenesis, Breast Cancer, Angiogenesis, Breast Cancer, Angiogenesis, Nigella sativa

\section{Background}

Reactive oxygen species, when produced in excessive amounts, can cause temporary or permanent damages to cellular macromolecules. These events trigger a variety of diseases such as cancer. To protect the cell, an antioxidant system including nutrients and enzymes like superoxide dismutase (SOD), catalase (CAT) and glutathione peroxidase (GPx) is used to neutralize reactive oxygen species (ROS) and lipid peroxides. It has been reported that cancer cells differ from normal ones in ROS production and enzymatic antioxidant activity. ROS production is much greater in cancer cells [1]. There is also a noticeable imbalance in the activity of antioxidant enzymes. It has been shown that products of oxidation, ROS, act as a promoting force in carcinogenesis [2]. Gosselin et al. [3] also suggested tumor emergence to be an outcome of the accumulation of ROS.

Soon after the tumor forms, angiogenesis is initiated by cancer cells to guarantee their constant access to nu- trients and oxygen in addition to waste discarding and to enable them to metastasize [4]. This process is known to more keenly begin and progress owing to vascular endothelial growth factor (VEGF), while endostatin is considered to suppress the process of angiogenesis [5]. Of all kinds of cancer, that of breast is the commonest invasive one amongst women. In 2012, the casualties in Iran numbered 3,304 people which equaled $14.2 \%$ of deaths by cancer [6]. Screening mammography can help reduce the casualties, to some extent, but it can be used after the problem has already happened [7]. In addition, the existing therapies and medicines have serious side effects. Moreover, Asian and Mediterranean populations are reported to experience less incidence of cancer [8]. Thus, nutrition and medicinal plants are getting more attention to prevent the problem. Amongst medicinal food is Nigella sativa L. whose black seeds offer various therapeutic benefits to settle headache, asthma, hypertension, eczema and gastrointestinal problems [9]. Its biological activity is mainly cred- 
ited to its main component, thymoquinone(TQ, MW:164.2, $\left.\mathrm{C}_{10} \mathrm{H}_{12} \mathrm{O}_{2}\right)[10]$. TQ has, reportedly, proved to possess antioxidant [11], anti-inflammatory [12] and anticancer activity [13]. In various experiments on murine models of fibrosarcoma and squamous cell carcinoma [14] as well as models of colon cancer [15] and prostate cancer [16], TQ offered to be promisingly anti-tumor. Also, TQ-induced pathways leading to apoptosis have been reported in many studies. Different extracts (ethanolic, methanolic, hexane etc.) obtained from the seeds have also been studied widely, reporting interesting results [17]. Therefore, in vivo anticancer and anti-angiogenic effects of $N$. sativa crude oil on breast cancer in animal model have yet to be clarified.

\section{Objectives}

Hence, in this study, we tried to examine the therapeutic role of orally consumed $\mathrm{N}$. sativa crude oil against tumor growth, oxidative damage and angiogenesis in BALB/C mice suffering from breast tumor.

\section{Materials and Methods}

In this clinical trial study, mice were maintained in a 12-hour period of darkness-light in $22^{\circ} \mathrm{C}$ temperature, throughout the study. This research was performed in winter and spring of 2012 in the neurovascular physiology research laboratory of Shahid Beheshti University. All the experiments were done according to the approved protocol of the ethics committee of the University of Shahid Beheshti (Tehran, Iran).

\subsection{N. sativa Crude Oil Preparation}

N. sativa seeds were purchased from farms in Semirom, Isfahan, Iran. After being authenticated at the school of pharmacy, Shahid Beheshti University of Medicinal Sciences, the seeds were cold-pressed to get the crude oil. The oil was then stored at $4^{\circ} \mathrm{C}$ in dark glass bottles. When needed, some was moved to a tube and used during the daily treatment of the mice.

\subsection{Extraction and Analysis of Volatile Oil}

One hundred milliliters of the crude oil was moved to a Clevenger-type apparatus and extracted with $500 \mathrm{~mL}$ of water for 4.5 hours (until no more essential oil was obtained). The collected essential oil was dried under anhydrous sodium sulphate and stored in sealed vials at $4^{\circ} \mathrm{C}$ until analysis. This volatile oil was analyzed by gas chromatography (GC) and gas chromatography-mass spectrometry (GC-MS) instruments. GC analysis was performed using a ThermoQuest gas chromatograph with a flame ionization detector (FID). The analysis was carried out on fused silica capillary DB-5 column $(30 \mathrm{~m} \times 0.25 \mathrm{~mm}$ i.d.; film thickness $0.25 \mu \mathrm{m}$ ). The injector and detector temperatures were kept at $250^{\circ} \mathrm{C}$ and $300^{\circ} \mathrm{C}$, respectively. Nitrogen was used as carrier gas at a flow rate of $1.1 \mathrm{~mL} / \mathrm{min}$; oven temperature program was $60-250^{\circ} \mathrm{C}$ at the rate of $4^{\circ} \mathrm{C} / \mathrm{min}$ and finally held isothermally for 10 minutes; split ratio was 1: 50. GC-MS analysis was carried out on a ThermoquestFinnigan Trace GC-MS instrument equipped with a DB-5 fused silica capillary column $(60 \mathrm{~m} \times 0.25 \mathrm{~mm}$ i.d.; film thickness $0.25 \mu \mathrm{m}$ ) coupled with a TRACE mass (Manchester, UK). Helium was used as the carrier gas at a flow rate of $1.1 \mathrm{~mL} / \mathrm{min}$ with split ratio of 1.50 . Mass range was from 45 to $456 \mathrm{amu}$ (atomic mass unit) with an ionizing voltage of $70 \mathrm{eV}$ (electron volte). Oven temperature program was the same given above for the GC (gas chromatography). The constituents of the essential oils were identified by calculation of their retention indices under temperatureprogrammed conditions for n-alkanes (C6 - C24) and the oil on a DB-5 column under the same chromatographic conditions. Identification of individual compounds was made by comparison of their mass spectra with those of the internal reference mass spectra library and confirmed by comparison of their retention indices with those of reported in the literature [18]. For quantification purpose, relative area percentages obtained by FID were used without the use of correction factors.

\subsection{Extraction and Analysis of Fixed Oil}

One milliliter of the crude oil was dissolved in $20 \mathrm{~mL}$ of $\mathrm{n}$-hexane and $2 \mathrm{~mL}$ of $2 \mathrm{~N}$ (normality) methanolic $\mathrm{KOH}$ was added. The mixture was stirred at $60^{\circ} \mathrm{C}$ for $30 \mathrm{~min}$ utes. After cooling, $2 \mathrm{~mL} 2 \mathrm{~N} \mathrm{HCl}$ was added and the mixture extracted with three $30 \mathrm{~mL}$ portion of EtOAc (ethyl acetate). Combined organic layer was dried over anhydrous $\mathrm{Na}_{2} \mathrm{SO}_{4}$ and concentrated under reduced pressure. This oil (as the methyl esters of the fatty acids) was analyzed through GC and GC-MS as mentioned above. Identification of the oil components was performed on the basis of their retention indices relative to the retention times of a series of n-alkanes, and by comparison of their mass spectra with those of NIST library data of the GC-MS system and Adams libraries spectra. Percentage of individual components was calculated based on GC peak areas without FID (flame ionization detector) response factor correction.

\subsection{Mice}

Inbred female BALB/c mice, 7 - 9 weeks old and weighing 18 - 20 g, were purchased from Pasture Institute of Iran, Karaj. With free access to food and water during the whole 
experiment, the mice were housed for one week under constant, standard conditions (12: 12 light/dark cycle, $22^{\circ} \mathrm{C}$ ) within the same facility.

\subsection{Tumor Induction}

Two days prior to the beginning of the experiment, all mice were subcutaneously transplanted with spontaneous murine mammary tumor (SMMT), volumes of less than 0.5 $\mathrm{cm}^{3}$, in the right flanks of mice, according to a previously tried protocol [19]. SMMT is an invasive carcinoma of ductal kind spontaneously developing in female BALB/c mice. The pieces, from a syngeneic donor, were transplanted into the right flank of the mice.

\subsection{Experimental Protocol}

The mice were caged into 4 groups ( 5 mice in each), randomly, and gavaged for 1 month, 2 days after tumor transplantation, as follows: The mice in the control group (CTRL) received distilled water daily following subcutaneous tumor transplantation. Mice within the next three groups (N. sativa $1, N$. sativa 2 and $N$. sativa 4 ), were respectively gavaged with 1, 2 and $4 \mathrm{~mL} / \mathrm{kg} /$ day of $N$. sativa crude oil.

\subsection{Tumor Volume Measurement}

When the tumors were palpable, the size of tumors was recorded using digital caliper twice a week. The tumor volume was calculated by the (Formula 1) below [19].

$V=\frac{1}{2} \times \mathrm{LW}^{2}$

$\mathrm{V}=$ volume, $\mathrm{L}=$ the length, $\mathrm{W}=$ the width.

On the last day of the experiment, the mice were sacrificed and the tumors were removed and kept frozen in $-80^{\circ} \mathrm{C}$ for further use. Prior to freezing and over ice-filled plates, the necrosis was rapidly removed.

\subsection{Tumor Sampling and Protein Extraction}

We followed the protocol used by earlier. Briefly, in 1 mL of a homogenizing buffer containing EDTA(ethylenediaminetetraacetic acid $)(1 \mathrm{mmol} / \mathrm{L})$, sucrose $(0.32 \mathrm{~mol} / \mathrm{L})$ and Tris-HCl (10 nmol/L; $\mathrm{pH}=7.4)$, small pieces of tumors were homogenized using a sonicator (Bandelin Sonopuls; HD 2070). We centrifuged the blend for 30 minutes at 13,600 $\times g$. Next, the supernatant was taken to measure superoxide dismutase and catalase activity. We adopted Bradford method to determine protein concentration [20].

\subsection{SOD Activity Measurement}

Through a previously practiced protocol, we assessed the total activity of superoxide dismutase as briefly follows: $1 \mathrm{~mL}$ of our mixhadpyrogallol $(0.48 \mathrm{mM})$, sodium phosphate buffer $(50 \mathrm{mM})$, enzymatic extract $(20 \mu \mathrm{L})$ and $\operatorname{EDTA}(0.1 \mathrm{mM})$. At $420 \mathrm{~nm}$, we monitored and recorded the changes in this mixture's absorbance at $25^{\circ} \mathrm{C}$ for 4 minutes and compared it to a blank buffer having all the mentioned elements except for the previously-prepared supernatant [20].

\subsection{Catalase Activity Measurement}

To measure catalase activity according to the method formerly mentioned, we prepared a mix ( $1 \mathrm{~mL}$ ) having hydrogen peroxide $(10 \mathrm{mM})$, sodium phosphate buffer (50 $\mathrm{mM} ; \mathrm{pH}=7.0)$ and enzymatic extract $(20 \mu \mathrm{L})$. We monitored and recorded the reduced absorbance of this mixture for 2 minutes at $240 \mathrm{~nm}$ at $25^{\circ} \mathrm{C}$ against a blank, i.e. with no the tissue homogenate [20].

\subsection{Western Blotting}

Briefly and regarding the previously practiced method [21] the samples were homogenized through sonication. The buffer contained $\mathrm{NaCl}(150 \mathrm{mM})$, EDTA (0.03\%), Tris$\mathrm{HCl}$ (50 mM, pH = 7.0), sodium deoxycholate (0.5\%), SDS (Sodium dodecyl sulfate) (0.1\%) and one tablet of protease inhibitor cocktail obtained from Roche. A total protein of $80 \mu \mathrm{g}$ obtained from all samples was loaded, with the protein ladder obtained from Thermo Scientific, into SDS-PAGE gel of $8 \%$ to be separated by size. PVDF (polyvinylidene difluoride) membranes (Millipore) were used to blot the proteins. The blots remained, for an hour, in blocking reagent (GE Health Care, US) at room temperature before incubation with specific primary antibodies to VEGF (Abcam 3109, 1: 1000), endostatin (Abcam 64569, 1: 500), and $\beta$-actin (Cell signaling 4967S, 1:1000) separately. Horseradish peroxide-conjugated secondary anti-rabbit antibody against $\beta$-actin (1: 1000, Dakocytomation) and HP-conjugated secondary anti-mouse antibody (1: 10000, Abcam 6728) against VEGF and endostatin were used afterwards to incubate the blots in room temperature for 1 hour. The immune-reactive proteins were detectable using chemoluminescence agents (Amersham Bioscience) while being exposed to films. Band images were quantified via Image software and densitometry analysis was performed after having normalized them with $\beta$-actin.

\subsection{Statistical Analysis}

Data on tumor volume were analyzed using factorial ANOVA. The enzymatic activity and the western blotting data were analyzed by one-way ANOVA. The post-hock test 
we used was LSD, SPSS-16 and statistical significance was reported as $\mathrm{P}<0.05$. Data were presented as mean \pm SD.

\section{Results}

\subsection{Volatile Oil}

The chemical composition of the volatile oil is listed in Table 1 . In total, 13 constituents comprising about $99.7 \%$ of the total oil were identified. Thymoquinone (39.25\%) and p-Cymene (43.54\%) were the most abundant components, followed by $\alpha$-thujene (10.16\%), 1-terpineol (1.68\%) and $\beta$ pinene $(1.08 \%)$ as the other main compounds.

Table 1. Chemical Composition of the Volatile Constituents of Nigella sativa

\begin{tabular}{lccc}
\hline No. & Compound Name & Retention Index & Percentage $(\%)$ \\
\hline $\mathbf{1}$ & $\alpha$-thujene & 927.84 & 10.16 \\
$\mathbf{2}$ & $\alpha$-Pinene & 934.54 & 1.00 \\
\hline $\mathbf{3}$ & Sabinene & 972.68 & 0.48 \\
\hline $\mathbf{4}$ & $\beta$-Pinene & 977.84 & 1.08 \\
\hline $\mathbf{6}$ & $\alpha$-Terpinene & 1016 & 0.17 \\
\hline $\mathbf{7}$ & p-Cymene & 1027.2 & 43.54 \\
\hline $\mathbf{8}$ & Limonene & 1029.2 & 1.01 \\
\hline $\mathbf{9}$ & $\gamma$-Terpinene & 1056 & 0.47 \\
\hline $\mathbf{1 0}$ & -Terpineol & 1116.4 & 1.68 \\
\hline $\mathbf{1 1}$ & 4-Terpineol & 1172.8 & 0.18 \\
\hline $\mathbf{1 2}$ & Thymoquinone & 1250.6 & 39.25 \\
\hline $\mathbf{1 3}$ & Carvacrol & 1295.5 & 0.34 \\
\hline & Junipene & 1400.4 & 0.35 \\
\hline
\end{tabular}

\subsection{Fixed Oil}

Five fatty acids were identified in the extract (Table 2), which represented about $99.9 \%$ of the total fatty acid composition. The extract consisted of two saturated fatty acids (14.69\%) and three unsaturated ones (85.23\%). Linoleic acid (63.85\%), oleic acid (17.85\%), and palmitic acid (11.21\%) were the major components. This fatty acid profile was comparable to those reported on the literature [22].

Tumor volumes: Analysis of the data on tumor volume showed that, as therapeutic, $N$. sativa crude oil at doses of 2 and $4 \mathrm{~mL} / \mathrm{kg} /$ day results in significantly reduced volumes $\left(147.26 \pm 10.84 \mathrm{~mm}^{3}\right.$ and $130.27 \pm 9.2 \mathrm{~mm}^{3}$, respectively; $\mathrm{P}=$ $0.001 ; \mathrm{n}=5)$ when compared to the control group $(274.5 \pm$ $30.8 \mathrm{~mm}^{3}$ ). No significant change was observed in N. sativa 1 tumor volumes (Figure 1).
Table 2. Fatty Acid Composition of Nigella sativa's Fixed Oil

\begin{tabular}{lccc}
\hline No. & Compound Name & $\begin{array}{c}\text { Retention Index (as } \\
\text { Methyl Ester) }\end{array}$ & Percentage(\%) \\
\hline $\mathbf{1}$ & Palmitic acid & 1922 & 11.21 \\
$\mathbf{2}$ & Linoleic acid & 2051 & 63.85 \\
\hline $\mathbf{3}$ & Oleic acid & 2053 & 17.85 \\
$\mathbf{4}$ & Stearic acid & 2059 & 3.48 \\
$\mathbf{5}$ & Eicosadienoic acid & 2271 & 3.53 \\
\hline
\end{tabular}

Figure 1. Effect of Nigella sativa's Crude Oil on Tumor Volume Against the Control Group

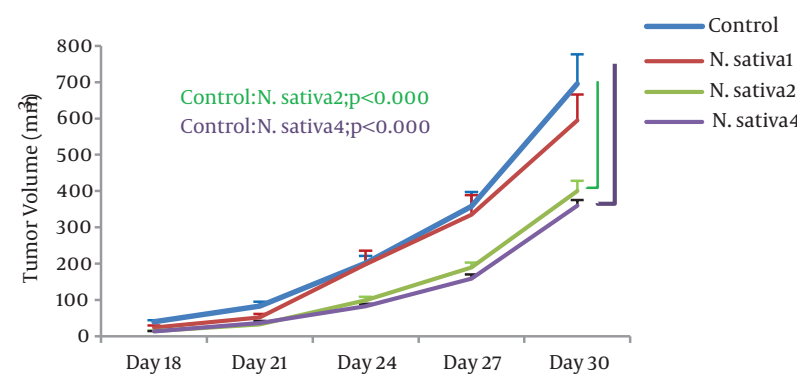

The mean $\pm S D$ is demonstrated above with $\mathrm{n}=5$ and $\mathrm{P}=0.001$. Mice were gavaged with 1,2 and $4 \mathrm{~mL} / \mathrm{kg} /$ day of $\mathrm{N}$. sativa oil for a month 2 days after tumor induction. Volumes were significantly reduced at 2 and $4 \mathrm{~mL} / \mathrm{kg} /$ day compared with the control volumes.

\subsection{Enzymatic Activity}

Both SOD and CAT activities, at doses of 2 and 4 $\mathrm{mL} / \mathrm{kg} /$ day of $N$. sativa crude oil, were significantly higher than those of the control group with, respectively, $\mathrm{P}=0.013$ and $\mathrm{P}=0.001$ for SOD activity $(\mathrm{n}=4)$ as well as $\mathrm{P}=0.003$ and $\mathrm{P}=0.001$ for CAT activity $(\mathrm{n}=4)$. Enzymatic antioxidant activity showed no significant change at the dose of 1 $\mathrm{mL} / \mathrm{kg} /$ day (Figures 2 and 3 ).

Western blotting: According to western blotting data analysis (Figures 4 and 5), 2 and $4 \mathrm{~mL} / \mathrm{kg} /$ day of $N$. sativa crude oil significantly decreased VEGF expression ( $\mathrm{P}=$ 0.001) while the endostatin expression was significantly elevated at the mentioned doses $(\mathrm{P}=0.006$ and $\mathrm{P}=0.001$, respectively).

\section{Discussion}

As indicated by our experiment, there was an increase in SOD activity in the tumor-bearing BALB/c mice treated with 2 and $4 \mathrm{~mL} / \mathrm{kg} /$ day of $N$. sativa crude oil, which was also accompanied by a significant tumor volume reduction. We, as well, recorded an increase in CAT activity in mice treated with 2 and $4 \mathrm{~mL} / \mathrm{kg} /$ day of $N$. sativa crude oil 


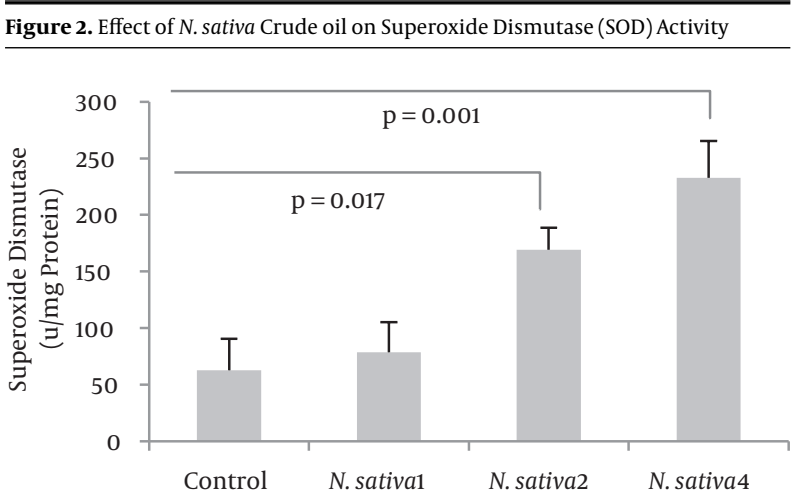

At the end of the 1-month treatment, all tumors were removed and assayed for SOD activity. At the doses of 2 and $4 \mathrm{~mL} / \mathrm{kg} /$ day, there was a higher SOD activity $(\mathrm{n}=4$; P $=0.013$ and $\mathrm{P}=0.001$, respectively) compared with the control group. Mean $\pm S D$ is illustrated above.

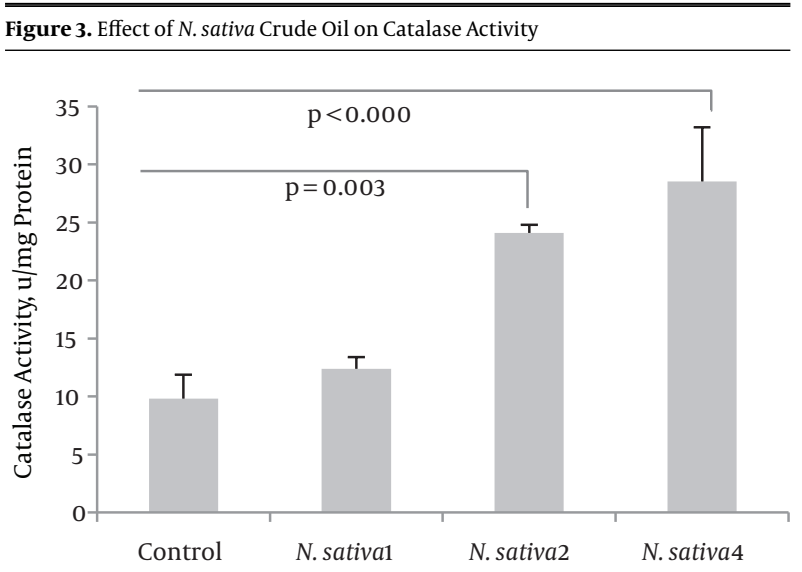

We assayed tumors at the end of the experiment to examine catalase (CAT) activity in comparison with the control group. There was an increase in catalase activity at doses of 2 and $4 \mathrm{~mL} / \mathrm{kg} / \operatorname{day}(\mathrm{n}=4 ; \mathrm{P}=0.003$ and $\mathrm{P}=0.001$, respectively). The illustration displays mean \pm SD.

as a therapeutic agent. The data showed 2 and $4 \mathrm{~mL} / \mathrm{kg}$ day of the crude oil could significantly increase endostatin levels and decrease VEGF amounts. According to our research, there has been no report on $N$. sativa crude oil effect on endostatin expression and this study, probably for the first time, has investigated such effect.

As mentioned earlier, oxidative stress is the result of what aerobic life greatly depends on oxidation. While aerobic cells enjoy this energy-producing reaction, they need to fight its harmful products at the same time [1]. To do so, organisms apply compound systems of antioxidants. Enzymes such as CAT and SOD are antioxidants essentially required for cells' self-protection. They are key players in several reactions which prevent and treat the harms of oxidative stress [1]. The members of the SOD family dismutate su-
Figure 4. VEGF Amount Alteration by N. sativa Crude Oil

\begin{tabular}{|l|l|l|l|l|}
\hline Protein Bands & CRTL & $\begin{array}{l}\text { N. } \\
\text { sativa } \\
1\end{array}$ & $\begin{array}{l}\text { N. } \\
\text { sativa } \\
2\end{array}$ & N. sativa 4 \\
\hline VEGF & \multicolumn{3}{|l}{} \\
\cline { 2 - 3 } & \multicolumn{3}{|l}{} \\
\cline { 2 - 3 } & \multicolumn{3}{|l}{} \\
\hline
\end{tabular}

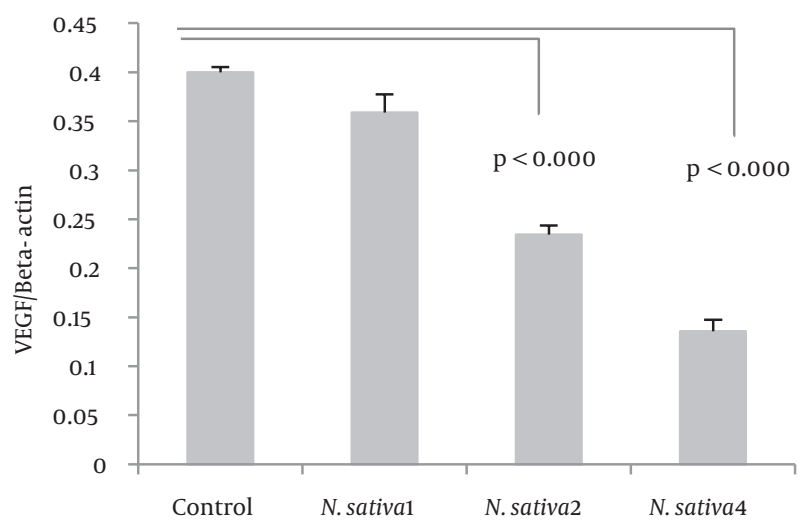

Mice gavaged with 2 (N. sativa 2 ) and $4 \mathrm{~mL} / \mathrm{kg} /$ day (N. sativa 4 ) of $N$. sativa crude oil showed lowered amounts of VEGF $[\mathrm{n}=4 ; \mathrm{P}=0.001]$. VEGF and $\beta$-actin bands in tumor tissues of BALB/c mice, obtained through western blotting, are shown. The graph shows the quantified data, as mean $\pm \mathrm{SD}$, through densitometric analysis. Note that $\beta$-actin was used as the normalizing loading control.

peroxide into oxygen and hydrogen peroxide. Thus, they take the vital step toward defense in oxygen-dependent cells. Several cancers are reported to be linked with deficiency in SOD. With no obvious oddities observed in mice lacking cytosolic SOD throughout their infancy and youth, the lifespan was shortened. A bigger rate of neoplastic changes was also reported and it seemed that, owing to oxidative stress resulted from lack of SOD, they suffered liver carcinoma in later life [23]. SOD has also been reported to be a suppressive agent against the formation and growth of tumor in prostate and human breast cancers. In an interesting study, all of the sampled patients with brain tumor showed significantly reduced SOD [24]. Some mechanisms of action have been suggested for SOD. One of these implies that, by producing $\mathrm{H}_{2} \mathrm{O}_{2}$, SOD functions as an apoptosis-triggering agent.

Superoxide anions are produced through a lot of reactions including inflammatory responses. A compound derived from SOD has been shown to scavenge these anions and prevent the development of tumor [25]. Recently, a substance able to mimic SOD was reported to perform 
Figure 5. Effect of Treatment with N. sativa Crude Oil on Endostatin Amounts

\begin{tabular}{|c|c|c|c|c|}
\hline Protein Bands & CRTL & $\begin{array}{l}N . \\
\text { sativa } \\
1\end{array}$ & $\begin{array}{l}N . \\
\text { sativa } \\
2\end{array}$ & N. sativa 4 \\
\hline \multicolumn{5}{|l|}{ Endostatin } \\
\hline$\beta$-actin & & & & \\
\hline
\end{tabular}

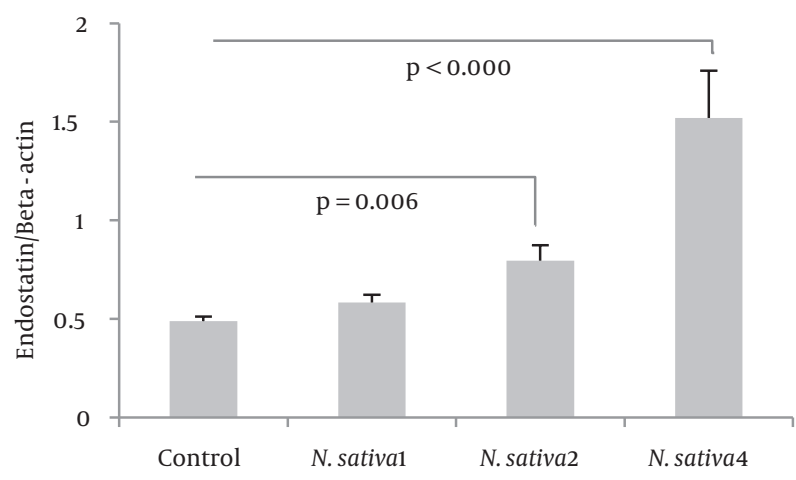

2 (N. sativa 2 ) and $4 \mathrm{~mL} / \mathrm{kg} /$ day (N. sativa 4 ) of $N$. sativa crude oil could increase endostatin amounts in tumor-bearing BALB/c mice $[\mathrm{n}=4 ; \mathrm{P}=0.006$ and $\mathrm{P}=0.001$ respectively]. $\beta$-actin and endostatin bands in tumor tissues, from western blotting, are presented. The graph illustrates the quantified data through densitometric analysis and mean $\pm \mathrm{SD}$ is shown. Again, $\beta$-actin was used as the normalizing loading control.

an array of actions in diseases related to oxidative stress [26]. N. sativa and its active component, TQ, are broadly reported to have wide antioxidant potential mainly due to their ability to alter the redox state and to scavenge free radicals and they seem to be executing these tasks through the modulation of antioxidant enzymes like SOD [27]. When it comes to the complete mechanism of CAT, we are so empty-handed. Yet, its importance in living beings is recognized as it breaks down hydrogen peroxide to water and oxygen. Reports indicated that CAT activity in liver was $22 \%$ less in cancer patients. Later, reports indicated that patients with malignant disease had reduced liver CAT activity. Lung inflammation apparently declines CAT activity and ends in a bigger amount of hydrogen peroxide within the cell, which benefits DNA damage and carcinogenesis [28]. Low activity of CAT is suggested to cause higher amounts of oxygen free radicals, therefore, is believed to advocate the oxidative stress in breast cancer [29]. On the other hand, high CAT activity was linked to a dropped risk of breast cancer, and a potential relationship between CAT activity and cancer was proposed [30]. As for N. sativa, many studies have shown it increases CAT activity and other antioxidant enzymes in heart, hypercholesterolemia and tissue culture [31] and this increase po- tentially benefits protection against cancer [32] and druginduced toxicity [33]. To survive, tumor cells can abuse a normally well-controlled mechanism, angiogenesis, so that new vessels outgrow from the existing ones toward the tumor mass [4]. Obviously, suppressing this odd ability can lead to tumor growth limitation. VEGF is considered the main factor initiating angiogenesis while endostatin has been known as an antiangiogenic factor [3]. In an experiment, it was shown that $N$. sativa's bioactive component, TQ, could suppress Akt and Erk signaling pathways which are believed to be the main angiogenic pathways activated in endothelial cells [11]. The experiment also reported the endothelial cells as more sensitive to TQ than cancer cells. In a more recent study on osteosarcoma, TQ was reported to act as an antitumor and antiangiogenic factor by affecting nuclear factor- $\kappa \mathrm{B}(\mathrm{NF}-\kappa \mathrm{B})$ pathway. Suppressing effect of TQ on VEGF expression and the subsequent angiogenesis was shown in zebrafish as well. Moreover, ROS seem to trigger VEGF expression and the activation of VEGF receptor 2 as well as HIF-1 (hypoxia induced factor-1) induction which consequently stimulates angiogenesis. Hence, by improving antioxidant activity, N. sativa indirectly exerts antiangiogenic effects as well [34]. Endostatin is reportedly responsible, as the major factor, for inhibition of angiogenesis and seems to suppress endothelial cells' proliferation and migration by affecting a variety of genes involved in cell cycle, anti-apoptosis and mitosis. It, the most notably, disrupts VEGF signaling pathways by preventing VEGF from binding with VEGFR2 (vascular endothelial growth factor-2) and by inhibiting the phosphorylation of the receptor, which in turn blocks subsequent signaling pathways [35]. As stated earlier, to our knowledge, there has been no research done on antiangiogenicor antioxidant effects of $N$. sativa crude oil, rather than TQ and our data shows for probably the first time how $N$. sativa crude oil affects angiogenesis as well as antioxidant activity within murine tumor tissue. Based on our findings and other work done on antioxidants and angiogenesis of N. sativa, we suggest that, possibly, by improving antioxidant enzymatic activities and suppressing angiogenesis, $N$. sativa crude oil enhances body's protection systems against cancer, yet more studies are necessary to further clarify the mechanisms.

\section{Acknowledgments}

This study was supported by the project grants (No: 1/92) awarded to Dr. Mohammad Reza Bigdeli from Shahid Beheshti University, and Razi herbal medicines research Center, Lorestan University of Medical Sciences. 


\section{Footnotes}

Authors' Contribution: All the experimental procedures, data analysis, and manuscript preparation were performed by Mrs. Sima Bahramian; supervised by Dr. Mohammad Reza Bigdeli and advised by Dr. Mahdi MoridiFarimani.

Funding/Support: Shahid Beheshti University, Tehran and Razi herbal medicines research center, Lorestan University of Medical Sciences.

\section{References}

1. Kattan Z, Minig V, Leroy P, Dauca M, Becuwe P. Role of manganese superoxide dismutase on growth and invasive properties of human estrogen-independent breast cancer cells. Breast Cancer Res Treat. 2008;108(2):203-15. doi: 10.1007/s10549-007-9597-5. [PubMed: 17473980].

2. Policastro L, Molinari B, Larcher F, Blanco P, Podhajcer OL, Costa CS, et al. Imbalance of antioxidant enzymes in tumor cells and inhibition of proliferation and malignant features by scavenging hydrogen peroxide. Mol Carcinog. 2004;39(2):103-13. doi:10.1002/mc.20001. [PubMed: 14750215].

3. Gosselin K, Martien S, Pourtier A, Vercamer C, Ostoich P, Morat L, et al. Senescence-associated oxidative DNA damage promotes the generation of neoplastic cells. Cancer Res. 2009;69(20):7917-25. doi: 10.1158/0008-5472.CAN-08-2510. [PubMed: 19826058].

4. Folkman J. Role of angiogenesis in tumor growth and metastasis. Semin Oncol. 2002;29(6 Suppl 16):15-8. doi: 10.1053/sonc.2002.37263. [PubMed: 12516034].

5. Eichhorn ME, Kleespies A, Angele MK, Jauch KW, Bruns CJ. Angiogenesis in cancer: molecular mechanisms, clinical impact. Langenbecks Arch Surg. 2007;392(3):371-9. doi: 10.1007/s00423-007-0150-0. [PubMed: 17458577].

6. Ferlay J, Soerjomataram I, Ervik M. Cancer incidence and mortality worldwide. Cancer base IARC. Available from: http://globocan.iarc.fr/ Default.aspx.

7. Feig SA. Effect of service screening mammography on population mortality from breast carcinoma. Cancer. 2002;95(3):451-7. doi 10.1002/cncr.10764. [PubMed: 12209736]

8. Wen W, Lu J, Zhang K, Chen S. Grape seed extract inhibits angiogenesis via suppression of the vascular endothelial growth factor receptor signaling pathway. Cancer Prev Res (Phila). 2008;1(7):554-61. doi: 10.1158/1940-6207.CAPR-08-0040. [PubMed:19139005].

9. Salem ML. Immunomodulatory and therapeutic properties of the Nigella sativa L. seed. Int Immunopharmacol. 2005;5(13-14):1749-70. doi:10.1016/j.intimp.2005.06.008. [PubMed:16275613].

10. Hajhashemi V, Ghannadi A, Jafarabadi H. Black cumin seed essential oil, as a potent analgesic and antiinflammatory drug. Phytother Res. 2004;18(3):195-9. doi:10.1002/ptr.1390. [PubMed:15103664].

11. Badary OA, Taha RA, Gamal el-Din AM, Abdel-Wahab MH. Thymoquinone is a potent superoxide anion scavenger. Drug Chem Toxicol. 2003;26(2):87-98. doi: 10.1081/DCT-120020404. [PubMed: 12816394]

12. El Gazzar M, El Mezayen R, Marecki JC, Nicolls MR, Canastar A, Dreskin SC. Anti-inflammatory effect of thymoquinone in a mouse model of allergic lung inflammation. Int Immunopharmacol. 2006;6(7):1135-42. doi: 10.1016/j.intimp.2006.02.004. [PubMed: 16714217].

13. Gali-Muhtasib H, Ocker M, Kuester D, Krueger S, El-Hajj Z, Diestel A, et al. Thymoquinone reduces mouse colon tumor cell invasion and inhibits tumor growth in murine colon cancer models. $J$ Cell Mol Med. 2008;12(1):330-42. doi: 10.1111/j.1582-4934.2007.00095.x. [PubMed: 18366456].
14. Yi T, Cho SG, Yi Z, Pang X, Rodriguez M, Wang Y, et al. Thymoquinone inhibits tumor angiogenesis and tumor growth through suppressing AKT and extracellular signal-regulated kinase signaling pathways. Mol Cancer Ther. 2008;7(7):1789-96. doi:10.1158/1535-7163.MCT-08-0124. [PubMed: 18644991].

15. Gali-Muhtasib H, Kuester D, Mawrin C, Bajbouj K, Diestel A, Ocker M, et al. Thymoquinone triggers inactivation of the stress response pathway sensor CHEK1 and contributes to apoptosis in colorectal cancer cells. Cancer Res. 2008;68(14):5609-18. doi:10.1158/0008-5472.CAN-080884. [PubMed: 18632613].

16. Li F, Rajendran P, Sethi G. Thymoquinone inhibits proliferation, induces apoptosis and chemosensitizes human multiple myeloma cells through suppression of signal transducer and activator of transcription 3 activation pathway. Br J Pharmacol. 2010;161(3):541-54. doi: 10.1111/j.1476-5381.2010.00874.x. [PubMed: 20880395].

17. Paarakh PM. Nigella sativa Linn.-A comprehensive review. India J Natural Product Resource. 2010;1(4):409-29.

18. Adams RP, Sparkman OD. Identification of essential oil components by gas chromatography/quadrupole mass spectroscopy. 4 ed. United States: Allured Pub Corp; 2005. pp. 1902-3.

19. Hajimoradi M, Hassan ZM, Pourfathollah AA, Daneshmandi S, Pakravan N. The effect of shark liver oil on the tumor infiltrating lymphocytes and cytokine pattern in mice. J Ethnopharmacol. 2009;126(3):565-70. doi: 10.1016/j.jep.2009.05.033. [PubMed: 19505554].

20. Bigdeli MR, Rasoulian B, Meratan AA. In vivo normobaric hyperoxia preconditioning induces different degrees of antioxidant enzymes activities in rat brain tissue. Eur J Pharmacol. 2009;611(1-3):22-9. doi: 10.1016/j.ejphar.2009.03.034. [PubMed: 19303405].

21. Mohammadi E, Bigdeli MR. Effects of preconditioning with normobaric hyperoxia on $\mathrm{Na}(+) / \mathrm{Ca}(2)(+)$ exchanger in the rat brain. Neuroscience. 2013;237:277-84. doi: 10.1016/j.neuroscience.2013.01.064. [PubMed: 23403180].

22. Piras A, Rosa A, Marongiu B. Chemical composition and in vitro bioactivity of the volatile and fixed oils of Nigella sativa L. extracted by supercritical carbon dioxide. Ind Crops Prod. 2013;46:317-23. doi: 10.1016/j.indcrop.2013.02.013.

23. Elchuri S, Oberley TD, Qi W, Eisenstein RS, Jackson Roberts L, Van Remmen $\mathrm{H}$, et al. CuZnSOD deficiency leads to persistent and widespread oxidative damage and hepatocarcinogenesis later in life. Oncogene. 2005;24(3):367-80. doi:10.1038/sj.onc.1208207. [PubMed: 15531919].

24. Aggarwal S, Subberwal M, Kumar S, Sharma M. Brain tumor and role of beta-carotene, a-tocopherol, superoxide dismutase and glutathione peroxidase. J Cancer Res Ther. 2006;2(1):24-7. [PubMed: 17998669].

25. Okada F, Shionoya H, Kobayashi M, Kobayashi T, Tazawa H, Onuma K, et al. Prevention of inflammation-mediated acquisition of metastatic properties of benign mouse fibrosarcoma cells by administration of an orally available superoxide dismutase. BrJCancer. 2006;94(6):85462. doi: 10.1038/sj.bjc.6603016. [PubMed: 16508635].

26. Wilcox CS. Effects of tempol and redox-cycling nitroxides in models of oxidative stress. Pharmacol Ther. 2010;126(2):119-45. doi: 10.1016/j.pharmthera.2010.01.003. [PubMed: 20153367].

27. Hamdy NM, Taha RA. Effects of Nigella sativa oil and thymoquinone on oxidative stress and neuropathy in streptozotocin-induced diabetic rats. Pharmacology. 2009;84(3):127-34. doi: 10.1159/000234466. [PubMed: 19684436].

28. Chung-man Ho J, Zheng S, Comhair SA, Farver C, Erzurum SC. Differential expression of manganese superoxide dismutase and catalase in lung cancer. Cancer Res. 2001;61(23):8578-85. [PubMed: 11731445].

29. Surapaneni KM, Gopan C. Status of lipid peroxidation and antioxidant enzymes in patients with carcinoma of breast. J Membrane Sci Res. 2007;15:21-4.

30. Ahn J, Gammon MD, Santella RM, Gaudet MM, Britton JA, Teitelbaum $\mathrm{SL}$, et al. Associations between breast cancer risk and the catalase genotype, fruit and vegetable consumption, and supplement use. Am 
J Epidemiol. 2005;162(10):943-52. doi: 10.1093/aje/kwi306. [PubMed: 16192345].

31. Barron J, Benghuzzi H, Tucci M. Effects of thymoquinone and selenium on the proliferation of $\mathrm{mg} 63$ cells in tissue culture. Biomed Sci Instrum. 2008;44:434-40. [PubMed: 19141954].

32. Khan MA, Tania M, Zhang DZ, Chen HCH. Antioxidant enzymes and cancer. Cardozo J Conflict Resolution. 2010;22(2):87-92.

33. Alenzi FQ, El-Bolkiny Yel S, Salem ML. Protective effects of Nigella sativa oil and thymoquinone against toxicity induced by the an- ticancer drug cyclophosphamide. Br J Biomed Sci. 2010;67(1):20-8. [PubMed: 20373678].

34. Peng L, Liu A, Shen Y, Xu HZ, Yang SZ, Ying XZ, et al. Antitumor and anti-angiogenesis effects of thymoquinone on osteosarcoma through the NF-kappaB pathway. Oncol Rep. 2013;29(2):571-8. doi: 10.3892/or.2012.2165. [PubMed: 23232982].

35. Folkman J. Antiangiogenesis in cancer therapy-endostatin and its mechanisms of action. Exp Cell Res. 2006;312(5):594-607. doi: 10.1016/j.yexcr.2005.11.015. [PubMed: 16376330]. 